\title{
Chiroptical properties of cryptophane-111 $\uparrow$
}

\author{
Thierry Buffeteau, (D) *a Delphine Pitrat, ${ }^{\mathrm{b}}$ Nicolas Daugey, ${ }^{\mathrm{a}}$ Nathalie Calin, ${ }^{\mathrm{b}}$ \\ Marion Jean, ${ }^{c}$ Nicolas Vanthuyne, ${ }^{c}$ Laurent Ducasse, ${ }^{a}$ Frank Wien ${ }^{d}$ and \\ Thierry Brotin*b
}

\begin{abstract}
The two enantiomers of cryptophane-111 (1), which possesses the most simplified chemical structure of cryptophane derivatives and exhibits the highest binding constant for xenon encapsulation in organic solution, were separated by HPLC using chiral stationary phases. The chiroptical properties of [CD $\left.(+)_{254}\right]-\mathbf{1}$ and $\left[\mathrm{CD}(-)_{254}\right]-\mathbf{1}$ were determined in $\mathrm{CH}_{2} \mathrm{Cl}_{2}$ and $\mathrm{CHCl}_{3}$ solutions by polarimetry, electronic circular dichroism (ECD), vibrational circular dichroism (VCD), and Raman optical activity (ROA) experiments and were compared to those of cryptophane-222 (2) derivative. Synchroton Radiation Circular Dichroism (SRCD) spectra were also recorded for the two enantiomers of 1 to investigate lowlying excited states in the ${ }^{1} \mathrm{~B}_{\mathrm{b}}$ region. Time-dependent density functional theory (TDDFT) calculations of the ECD and SRCD as well as DFT calculations of the VCD and ROA allowed the [CD $\left.(-)_{254}\right]-P P-1$ and [CD $\left.(+)_{254}\right]-M M-1$ absolute configurations for 1 in $\mathrm{CH}_{2} \mathrm{Cl}_{2}$ and $\mathrm{CHCl}_{3}$ solutions. Similar configurations were found in the solid state from $\mathrm{X}$-ray crystals of the two enantiomers but the chemical structures are significantly different from the one calculated in solution. In addition, the chiroptical properties of the two enantiomers of $\mathbf{1}$ were independent of the nature of the solvent, which is significantly different to that observed for cryptophane-222 compound. The lack of solvent molecule $\left(\mathrm{CH}_{2} \mathrm{Cl}_{2}\right.$ or $\left.\mathrm{CHCl}_{3}\right)$ within the cavity of $\mathbf{1}$ can explain this different behaviour between $\mathbf{1}$ and $\mathbf{2}$. Finally, we show in this article that the encapsulation of xenon by 1 can be evidenced by ROA following the symmetric breathing mode of the cryptophane-111 skeleton at $150 \mathrm{~cm}^{-1}$.
\end{abstract}

\section{Introduction}

The cryptophane backbone displays a very simple and easily recognizable chemical structure, which is composed of six aromatic rings positioned into a rigid molecular frame. ${ }^{1,2}$ The six aromatic rings are assembled into two independent cyclotribenzylene (CTB) sub-units connected together by three

\footnotetext{
${ }^{a}$ Bordeaux University, Institut des Sciences Moléculaires, CNRS UMR 5255, 33405 Talence, France.E-mail: t.buffeteau@ism.u-bordeaux1.fr

${ }^{b}$ Lyon 1 University, Ecole Normale Supérieure de Lyon, CNRS UMR 5182, Laboratoire de Chimie, 69364 Lyon, France.E-mail: thierry.brotin@ens-lyon.fr

${ }^{c}$ Aix-Marseille University, CNRS, Centrale Marseille, iSm2, Marseille, France

${ }^{d}$ Synchrotron SOLEIL, L'Orme des Merisiers, 91192 Gif sur Yvette, France
}

linkers, whose length and nature can be varied. This structure generates a lipophilic cavity that can accommodate a large variety of guest molecules, such as halogenomethanes and ammonium salts, or atoms in organic or aqueous solutions. ${ }^{2}$ The cryptophane-111 skeleton (compound 1 in Scheme 1) appears as the most simplified structure of cryptophane derivatives and its synthesis has been reported for the first time in $2007 .^{3}$ This compound exhibits the highest binding constant $\left(10^{4} \mathrm{M}^{-1}\right.$ at $293 \mathrm{~K}$ ) for xenon encapsulation in organic solvent but it does not bind halogenomethanes due to its small internal cavity. ${ }^{3,4}$ In 2010, Rousseau and co-workers published a high-yielding scalable

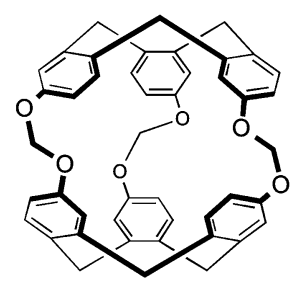

1

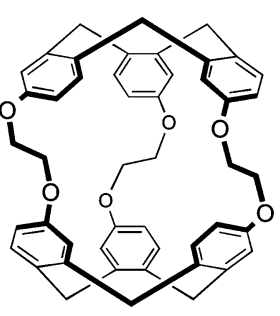

Scheme 1 Chemical structures of $P P-1$ and $P P-2 .^{18,19}$ 
synthesis of this derivative by optimizing the cyclotriphenolene unit dimerization, ${ }^{5}$ whereas Holman and co-workers reported the $\mathrm{X}$-ray structure of the racemate of $\mathbf{1}$ and the first water-soluble cryptophane-111 with Ru complexes. ${ }^{6}$ Later, in 2011, Rousseau and co-workers published the synthesis of a metal-free watersoluble cryptophane-111. ${ }^{7}$ Finally, Holman and co-workers reported the first rim-functionalized derivatives of cryptophane-111 ((MeO) $)_{3}-111$ and $\left.\mathrm{Br}_{3}-111\right)$, which limit the range of achievable conformations of the cryptophane-111 skeleton, ${ }^{8}$ and they also showed the very high thermal stability (up to about $300{ }^{\circ} \mathrm{C}$ ) of the Xe@1 complex in the solid state. ${ }^{9}$

Besides their interesting binding properties, most of the cryptophane derivatives exhibit an inherently chiral structure due to the anti arrangement of the linkers or to the presence of two different CTB caps. Thus, the anti arrangement of the methylenedioxy linkers makes $\mathbf{1}$ a chiral molecule. During the past decade, we have thoroughly investigated enantiopure cryptophanes using several techniques such as polarimetry, electronic circular dichroism (ECD), vibrational circular dichroism (VCD), and Raman optical activity (ROA) because the chiroptical properties of these derivatives are extremely sensitive to the encapsulation of guest molecules. ${ }^{10-17}$ For instance, water-soluble cryptophanes display unique chiroptical properties depending on the nature of the guest (neutral or charged species) present within the cavity of the host. ${ }^{10-14}$ In addition, cryptophane-222 (compound 2 in Scheme 1) possesses unusual chiroptical properties in organic solvents never observed before with cryptophane derivatives. ${ }^{17}$ Indeed, a very different behaviour of the specific optical rotation (SOR) values was observed in the nonresonance region above $365 \mathrm{~nm}$ in $\mathrm{CHCl}_{3}$ and $\mathrm{CH}_{2} \mathrm{Cl}_{2}$ solutions. This feature was related to conformational changes of the three ethylenedioxy linkers upon encapsulation of the two solvent molecules by 2 . This explanation could be confirmed by investigating the chiroptical properties of the new derivative 1. Indeed, 1 differs from 2 only by the length of the three linkers connecting the two CTB units, leading to a smaller size of the cavity. Moreover, the three portals of $\mathbf{1}$ are too small to allow any solvent molecules to enter the cavity of the host. Even $\mathrm{CH}_{2} \mathrm{Cl}_{2}\left(V_{\mathrm{vdW}}=52 \AA^{3}\right)$ is too large to cross the portals of $\mathbf{1}$, leaving the cavity only accessible for smaller guests such as methane or xenon. ${ }^{4}$ In addition, the replacement of ethylenedioxy by methylenedioxy linkers presents the advantage to decrease the number of conformations for the three bridges. Thus, we believe that the two enantiomers of $\mathbf{1}$ are important compounds for understanding the role of the solvent on the chiroptical properties of cryptophane derivatives in general. A change of the chiroptical properties of 1 regardless of the nature of the solvent will tend to demonstrate that the bulk solvent plays an important role in the chiroptical properties of cryptophane. In contrast, a lack of modification on the chiroptical properties of 1 will show that only the solvent molecule present within the cavity of the cryptophanes (that is the case for 2) has an effect on their chiroptical properties.

In this article we focus our attention on the chiroptical properties of 1 since they have never been reported in the literature, probably due to the difficulties encountered for the optical resolution of $\mathbf{1}$ into its two enantiomers (+)-1 and (-)-1.
In addition, the simplified chemical structure of $\mathbf{1}$ (87 atoms) allows more sophisticated theoretical calculations (better basis set) for the prediction of the VCD, ROA and ECD spectra by using density functional theory (DFT and time-dependent DFT) methods.

We report in this article the separation of the two enantiomers of 1 by high-performance liquid chromatography (HPLC) using chiral stationary phases and the detailed study of their chiroptical properties in $\mathrm{CHCl}_{3}$ and $\mathrm{CH}_{2} \mathrm{Cl}_{2}$ solutions by polarimetry, ECD, VCD, and ROA spectroscopy. Synchrotron Radiation Circular Dichroism (SRCD) spectra of the two enantiomers of $\mathbf{1}$ were also recorded in the two solvents to investigate the low-lying excited states in the ${ }^{1} \mathrm{~B}_{\mathrm{b}}$ region (190-220 nm). The chiroptical properties of 1 were compared to those recently published for $2 .{ }^{17}$ DFT and TD-DFT calculations were performed to predict SOR values as well as the ECD, VCD, and ROA spectra for several geometries of 1. The X-ray structures of these two enantiomers were also reported and compared to the optimized geometries of 1 calculated by DFT. Finally, the xenon encapsulation by $\mathbf{1}$ was followed by VCD and ROA spectroscopy.

\section{Experimental}

\section{X-ray crystallography}

X-ray structures of the two enantiomers of 1 were obtained from crystals mounted on a Kappa geometry diffractometer $(\mathrm{Cu}$ radiation) and using the experimental procedure previously published. ${ }^{16}$

CCDC 1537591 and 1537585 contain the crystallographic data of $\left[\mathrm{CD}(+)_{254}\right]-\mathbf{1}$ and $\left[\mathrm{CD}(-)_{254}\right]-\mathbf{1}$, respectively. $\dagger$

\section{Polarimetric, UV-vis and ECD measurements}

Optical rotations of the two enantiomers of $\mathbf{1}$ were measured in two solvents $\left(\mathrm{CHCl}_{3}, \mathrm{CH}_{2} \mathrm{Cl}_{2}\right)$ at several wavelengths $(589,577$, 546,436 , and $365 \mathrm{~nm}$ ) using a polarimeter with a $10 \mathrm{~cm}$ cell thermostated at $25{ }^{\circ} \mathrm{C}$. Concentrations used for the polarimetric measurements were typically in the range $0.22-0.27 \mathrm{~g} /$ $100 \mathrm{~mL}$. ECD spectra of the two enantiomers of 1 were recorded in four solvents $\left(\mathrm{CHCl}_{3}, \mathrm{CH}_{2} \mathrm{Cl}_{2}\right.$, tetrahydrofuran (THF) and $\mathrm{CH}_{3} \mathrm{CN}$ ) at $20{ }^{\circ} \mathrm{C}$ with a $0.2 \mathrm{~cm}$ path length quartz cell (concentrations were in the range $5 \times 10^{-5}-1 \times 10^{-4} \mathrm{M}$ ). Spectra were recorded in the wavelength ranges of $210-400 \mathrm{~nm}$ (THF and $\left.\mathrm{CH}_{3} \mathrm{CN}\right)$ or $230-400 \mathrm{~nm}\left(\mathrm{CH}_{2} \mathrm{Cl}_{2}\right.$ and $\left.\mathrm{CHCl}_{3}\right)$ with a $0.5 \mathrm{~nm}$ increment and a $1 \mathrm{~s}$ integration time. Spectra were processed with standard spectrometer software, baseline corrected and slightly smoothed by using a third order least square polynomial fit. UV-vis spectra of the two enantiomers of 1 were recorded in $\mathrm{CH}_{2} \mathrm{Cl}_{2}$ (230-400 nm) and THF (210-400 nm) at $20{ }^{\circ} \mathrm{C}$ with a 0.5 and $0.2 \mathrm{~cm}$ path lengths quartz cell, respectively.

\section{SRCD measurements}

Synchrotron Radiation Circular Dichroism (SRCD) measurements were carried out at the DISCO beam-line, SOLEIL synchrotron. ${ }^{20,21}$ Samples of the two enantiomers of $\mathbf{1}$ were dissolved in $\mathrm{CH}_{2} \mathrm{Cl}_{2}$ and $\mathrm{CHCl}_{3}$. Serial dilutions of the concentrations in view of data 
collection in three spectral regions were chosen between $100 \mathrm{~g} \mathrm{~L}^{-1}$, $10 \mathrm{~g} \mathrm{~L}^{-1}$ to $2.5 \mathrm{~g} \mathrm{~L}^{-1}$. Accurate concentrations were reassessed by absorption measurements allowing the scaling of spectral regions to each other. Samples were loaded in circular demountable $\mathrm{CaF}_{2}$ cells of $3.5 \mu \mathrm{m}$ path lengths, using $2-4 \mu \mathrm{L}{ }^{22}$ Two consecutive scans for each spectral region of the corresponding dilution, were carried out for consistency and repeatability. CD-spectral acquisitions of $1 \mathrm{~nm}$ steps and $1 \mathrm{~nm}$ bandwith, between 320-255 nm, 260-216 nm and $232-170 \mathrm{~nm}$ were performed at $1.2 \mathrm{~s}$ integration time per step for the samples. Averaged spectra were then subtracted from corresponding averaged baselines collected three times. The temperature was set to $20{ }^{\circ} \mathrm{C}$ with a Peltier controlled sample holder. Prior, (+)-camphor-10-sulfonic acid was used to calibrate amplitudes and wavelength positions of the SRCD experiment. Data-treatment including averaging, baseline subtraction, smoothing, scaling and standardisation were carried out with CDtool. ${ }^{23}$

\section{IR and VCD measurements}

The IR and VCD spectra were recorded on an FTIR spectrometer equipped with a VCD optical bench, ${ }^{24}$ following the experimental procedure previously published. ${ }^{16}$ Samples were held in a $250 \mu \mathrm{m}$ path length cell with $\mathrm{BaF}_{2}$ windows. IR and VCD spectra of the two enantiomers of 1 were measured in $\mathrm{CDCl}_{3}$ and $\mathrm{CD}_{2} \mathrm{Cl}_{2}$ solvents at a concentration of $0.015 \mathrm{M}$. Additional spectra were measured in $\mathrm{CDCl}_{3}$ in presence of xenon.

\section{ROA measurements}

Raman and ROA spectra were recorded on a ChiralRAMAN spectrometer, following the experimental procedure previously published. ${ }^{15}$ The two enantiomers of $\mathbf{1}$ were dissolved in $\mathrm{CDCl}_{3}$ and $\mathrm{CD}_{2} \mathrm{Cl}_{2}$ solvents at a concentration of $0.1 \mathrm{M}$ and filled into fused silica microcell $(4 \times 3 \times 10 \mathrm{~mm})$. The laser power was $200 \mathrm{~mW}(\sim 80 \mathrm{~mW}$ at the sample). The presented spectra in $\mathrm{CDCl}_{3}\left(\mathrm{CD}_{2} \mathrm{Cl}_{2}\right)$ are an average over about $32(52) \mathrm{h}$. Additional experiments were performed in the two solvents in presence of xenon.

\section{Theoretical calculations}

All DFT and TDDFT calculations were carried out with Gaussian $09 .{ }^{25}$ Preliminary conformer distribution search of 1 was performed at the molecular mechanics level of theory, employing MMFF94 force fields incorporated in ComputeVOA software package. Twenty one conformers were found within roughly $8 \mathrm{kcal} \mathrm{mol}^{-1}$ of the lowest energy conformer. Their geometries were optimized at the DFT level using B3PW91 functional ${ }^{26}$ and $6-31 G^{* *}$ basis set, ${ }^{27}$ leading to ten different conformers within a energetic window of $7.5 \mathrm{kcal} \mathrm{mol}^{-1}$. Finally, only the three lowest energetic geometries were kept, and reoptimized with the use of IEFPCM model of solvent $\left(\mathrm{CH}_{2} \mathrm{Cl}_{2}\right.$ and $\left.\mathrm{CHCl}_{3}\right){ }^{28,29}$ Vibrational frequencies, IR and VCD intensities, and ROA intensity tensors (excitation at $532 \mathrm{~nm}$ ) were calculated at the same level of theory. For comparison to experiment, the calculated frequencies were scaled by 0.968 and the calculated intensities were converted to Lorentzian bands with a full-width at half-maximum (FWHM) of $9 \mathrm{~cm}^{-1}$.
Optical rotation calculations have been carried out at several standard wavelengths $(365,436,532$ and $589 \mathrm{~nm})$ by means of DFT methods (B3PW91/6-31G**) for the three conformers reoptimized with the use of PCM solvent model.

ECD spectra were calculated at the time-dependent density functional theory (TDDFT) level using the MPW1K functional ${ }^{30}$ and the $6-31+G^{*}$ basis set. Calculations were performed for the three conformers reoptimized with the use of PCM solvent model $\left(\right.$ IEFPCM $=\mathrm{CH}_{2} \mathrm{Cl}_{2}$ ), considering 120 excited states. For comparison to experiment, the rotational strengths were converted to Gaussian bands with a FWHM of $0.1 \mathrm{eV}$.

\section{Results}

\section{Synthesis and HPLC separation of the two enantiomers of 1}

The racemic mixture of $\mathbf{1},(r a c)-\mathbf{1}$, was prepared according to a known procedure (Fig. S1 in the ESI $\dagger$ ). ${ }^{3}$ Compound 1 does not possess any substituent that could be exploited for separating the two enantiomers of $\mathbf{1}$ by the formation of diastereomeric derivatives. Consequently, the two enantiomers of 1 were separated using a chiral HPLC column (Chiralpak ID, eluent: heptane/EtOH/ $\mathrm{CHCl}_{3} 50 / 30 / 20,1 \mathrm{~mL} \mathrm{~min}^{-1}$ ), which allowed the efficient separation of the two enantiomers of $\mathbf{1}$ with an excellent resolution factor $\left(R_{\mathrm{s}}=3.24\right)$, as shown in Fig. 1 . A circular dichroism detector provided the sign of each enantiomer at $254 \mathrm{~nm}$. It was observed that enantiomer $\left[\mathrm{CD}(-)_{254}\right]-\mathbf{1}$ was first eluted at $t=6.83 \mathrm{~min}$, followed by enantiomer $\left[\mathrm{CD}(+)_{254}\right]-1$ at $t=9.02 \mathrm{~min}$. To obtain the two enantiomers in fair quantities, a semipreparative Chiralpak ID column $(250 \times 10 \mathrm{~mm}$, eluent:

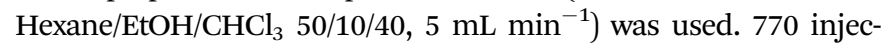
tions $(170 \mu \mathrm{L})$ every $1.8 \mathrm{~min}$ were necessary to separate $350 \mathrm{mg}$ of the racemic mixture of $\mathbf{1}$. The first eluted enantiomer, $\left[\mathrm{CD}(-)_{254}\right] \mathbf{- 1}$, was collected between 4.1 and $4.7 \mathrm{~min}$ and the second one, $\left[\mathrm{CD}(+)_{254}\right]-\mathbf{1}$, between 5.0 and $5.6 \mathrm{~min}$. After this semipreparative separation, the enantiomeric excess (ee) of the two collected enantiomers was measured by analytical HPLC (Fig. S2 in the

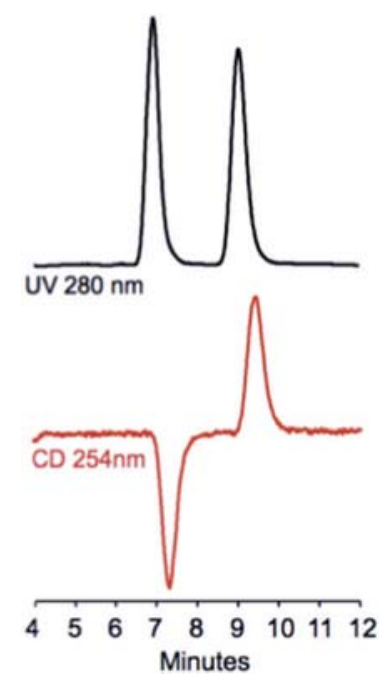

Fig. 1 Separation of the two enantiomers of 1 using an analytical chiral HPLC column. 
ESI $\dagger$ ). Thus, from $350 \mathrm{mg}$ of racemic material, $160 \mathrm{mg}$ of each enantiomer were obtained with an excellent enantiomeric excess (ee $>99 \%$ for $\left[\mathrm{CD}(-)_{254}\right]^{-1}$ and ee $>99.5 \%$ for $\left.\left[\mathrm{CD}(+)_{254}\right]-\mathbf{1}\right)$. In order to improve the chemical purity of the two compounds, an additional purification step was conducted on both enantiomers. Thus, compounds $\left[\mathrm{CD}(+)_{254}\right]-\mathbf{1}$ and $\left[\mathrm{CD}(-)_{254}\right]-\mathbf{1}$ were purified on silica gel (eluent: $\mathrm{CH}_{2} \mathrm{Cl}_{2}$ /acetone 90/10) and then recrystallized in a mixture of $\mathrm{CH}_{2} \mathrm{Cl}_{2} / \mathrm{EtOH}$. These additional purification steps provide both enantiomers with high chemical purity. The ${ }^{1} \mathrm{H}$ NMR and ${ }^{13} \mathrm{C}$ NMR spectra (Fig. S3-S6 in the ESI $\dagger$ ) are identical to those reported for $(r a c)-\mathbf{1}$.

\section{X-ray crystallographic structures of the two enantiomers of 1}

$\mathrm{X}$-ray crystals of $\left[\mathrm{CD}(+)_{254}\right]-\mathbf{1}$ and $\left[\mathrm{CD}(-)_{254}\right]-\mathbf{1}$ were obtained in a $\mathrm{CH}_{2} \mathrm{Cl}_{2} / \mathrm{EtOH}$ mixture and in pyridine, respectively (Fig. S7a and $b$ in the ESI $\dagger$ ). The crystallographic data of the two X-ray crystal structures are reported in the ESI, $\dagger$ (Table S1).

Compounds $\left[\mathrm{CD}(-)_{254}\right]-1$ and $\left[\mathrm{CD}(+)_{254}\right]-1$ crystallize in $P 2_{1} 2_{1} 2_{1}$ and $P 2_{1}$ space groups, respectively. No disorder was observed in the two X-ray structures and the cavities do not contain any substrate (solvent or gas molecules). The two enantiomers adopt a contracted conformation of the bridges that minimizes the internal cavity volume. Using a probe radius of $1.4 \AA$, the estimated cavity volume of $\left[\mathrm{CD}(+)_{254}\right]-1$ and $\left[\mathrm{CD}(-)_{254}\right]-1$ were 30 and $32 \AA^{3}$, respectively. It is noteworthy that these two X-ray structures are significantly different from the one reported for the racemate. ${ }^{6}$ Indeed, the X-ray structures of the two enantiopure derivatives adopt a more flattened shape with respect to the X-ray structure of the racemate, characterized by a large twist angle of $55.3^{\circ}$ between the two CTB caps. ${ }^{31}$ For the racemate, a twist angle of $18.1^{\circ}$ was found between the two CTB caps, associated with a cavity volume of $72 \AA^{3}{ }^{6}$. Interestingly, these structures are also less symmetrical than the one observed for racemate and a topview of these two structures reveals that the six benzene rings are totally eclipsed (Fig. S8 in the ESI $\dagger$ ). In contrast, the X-ray structure of the racemic derivative shows a strong overlapping of the phenyl rings.

\section{Polarimetry and electronic circular dichoism}

The two enantiomers of $\mathbf{1}$ are well soluble in $\mathrm{CH}_{2} \mathrm{Cl}_{2}$ and $\mathrm{CHCl}_{3}$ but unfortunately they show poor solubility in other organic solvents. Thus, polarimetric experiments were performed only in $\mathrm{CH}_{2} \mathrm{Cl}_{2}$ and $\mathrm{CHCl}_{3}$ solutions. The specific optical rotation (SOR) values of the two enantiomers of $\mathbf{1}$ are reported in the $\mathrm{ESI}, \dagger$ (Table S2) and the wavelength dependence of $\left[\mathrm{CD}(+)_{254}\right]-1$

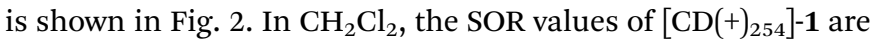
slightly positive at 589 and $577 \mathrm{~nm}$, close to zero at $546 \mathrm{~nm}$ and significantly negative at 436 and $365 \mathrm{~nm}$. Nevertheless, despite the low values measured for this compound at 589, 577 and $546 \mathrm{~nm}$, SOR values with opposite sign are obtained for the two enantiomers of 1 (Table S2, ESI $\dagger$ ). In $\mathrm{CHCl}_{3}$, the wavelength dependence of the SOR values evolves similarly with values slightly higher. This result contrasts with the measurements performed with compound 2 that exhibited significant differences in $\mathrm{CH}_{2} \mathrm{Cl}_{2}$ and $\mathrm{CHCl}_{3}$ solutions. Finally, as previously observed with compound $2,{ }^{17}$ a change of the SOR sign is

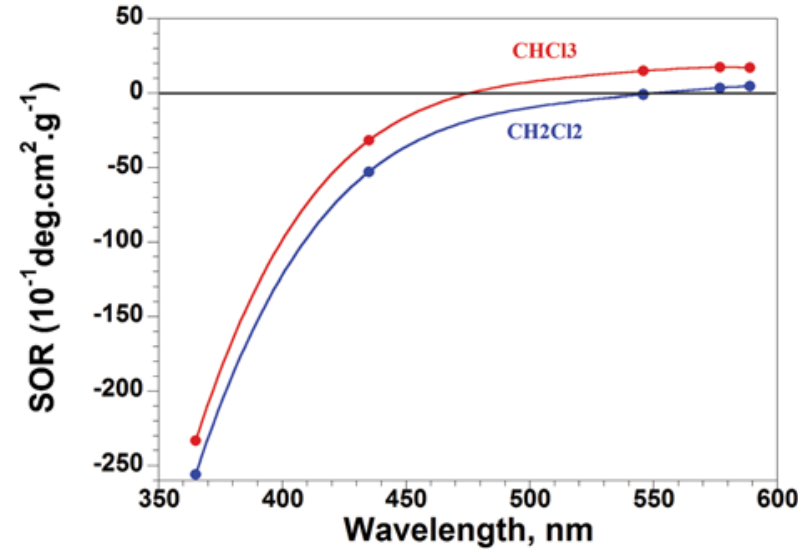

Fig. 2 Specific optical rotation values $\left(10^{-1} \mathrm{deg} \mathrm{cm}^{2} \mathrm{~g}^{-1}\right)$ of $\left[C D(+)_{254}\right]-1$ recorded at several wavelengths $(365,436,546,577$ and $589 \mathrm{~nm}$ ) in chloroform ( $c=0.22$ ), and dichloromethane $(c=0.27)$ solvents.

observed in the nonresonant region (around $546 \mathrm{~nm}$ in $\mathrm{CH}_{2} \mathrm{Cl}_{2}$ and $475 \mathrm{~nm}$ in $\mathrm{CHCl}_{3}$ ).

UV-Vis and ECD experiments require lower concentration of solute and consequently this allows us to extend the range of solvents. Thus, UV-Vis and ECD spectra of $\left[\mathrm{CD}(+)_{254}\right]-\mathbf{1}$ and $\left[\mathrm{CD}(-)_{254}\right]-1$ were successfully recorded in $\mathrm{CH}_{2} \mathrm{Cl}_{2}, \mathrm{CHCl}_{3}$, THF, and $\mathrm{CH}_{3} \mathrm{CN}$ solvents. The UV-Vis spectra measured in THF and $\mathrm{CH}_{2} \mathrm{Cl}_{2}$ solvents are reported in Fig. S9 in the ESI. $\dagger$ These spectra are very similar to those published for compound $2 .{ }^{17}$ The ECD spectra of the two enantiomers are reported in Fig. S10 in the ESI, $\dagger$ for the four solvents. A perfect mirror image is observed in all solvents for the two enantiomers as expected for enantiomers with high enantiomeric excess. For $\mathrm{CH}_{2} \mathrm{Cl}_{2}$ and $\mathrm{CHCl}_{3}$ solutions, the ECD spectra give only access to the bands corresponding to the two forbidden ${ }^{1} \mathrm{~L}_{\mathrm{a}}$ and ${ }^{1} \mathrm{~L}_{\mathrm{b}}$ transitions in the UV-visible region (230-300 nm). For THF and $\mathrm{CH}_{3} \mathrm{CN}$ solutions, the spectral range can be extended up to $210 \mathrm{~nm}$. This allows us to have access to another spectral region corresponding to the allowed ${ }^{1} \mathrm{~B}_{\mathrm{b}}$ transition. This spectral region usually gives rise to intense ECD signals in organic solution. It was observed that the ECD spectra of $\left[\mathrm{CD}(+)_{254}\right]-1$ and $\left[\mathrm{CD}(-)_{254}\right]-\mathbf{1}$ are very similar in shape and intensity, regardless of the nature of the solvent used in these experiments. For instance, in $\mathrm{CH}_{2} \mathrm{Cl}_{2}$ the ECD spectrum of the $\left[\mathrm{CD}(+)_{254}\right]-1$ enantiomer shows four bands, as shown in Fig. 3. Three ECD bands (two negative and one slightly positive from high to low wavelengths) are observed in the spectral region related to the ${ }^{1} \mathrm{~L}_{\mathrm{b}}$ transition (260-300 $\mathrm{nm}$ ). At shorter wavelengths, only a single positive ECD band was observed between 230 and $255 \mathrm{~nm}\left({ }^{1} \mathrm{~L}_{\mathrm{a}}\right.$ transition). Interestingly, it can be noticed that the ECD spectra of $\left[\mathrm{CD}(+)_{254}\right]-\mathbf{1}$ and $\left[\mathrm{CD}(-)_{254}\right]-2$ show a lot of similarities even though some significant spectral differences are observed especially in the ${ }^{1} \mathrm{~L}_{\mathrm{a}}$ region. Indeed, the bisignate ECD signal usually observed in the ${ }^{1} \mathrm{~L}_{\mathrm{a}}$ region for cryptophane derivatives and observed for $\left[\mathrm{CD}(-)_{254}\right]-2$ is no longer present in the ECD spectrum of $\left[\mathrm{CD}(+)_{254}\right]-\mathbf{1}$. In the past, the sign of this bisignate ECD signal was exploited to determine the absolute configuration (AC) of cryptophane-A molecule. ${ }^{32}$ Then, we have 


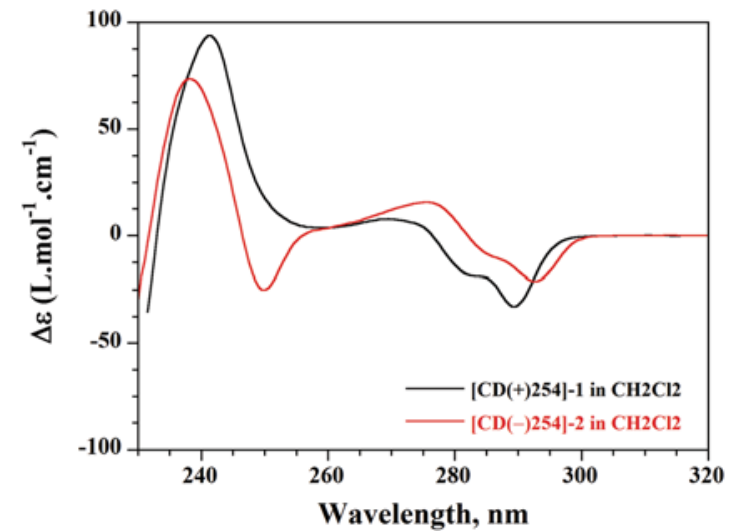

Fig. 3 Comparison of experimental ECD spectra of $\left[C D(+)_{254}\right]-1$ (black spectrum) and $\left[\mathrm{CD}(-)_{254}\right]-2$ (red spectrum) in $\mathrm{CH}_{2} \mathrm{Cl}_{2}$ solution.

confirmed that this approach could be used to assign the AC of other cryptophane derivatives in organic solution. This study shows that the approach can not be used for cryptophane-111.

Synchrotron radiation circular dichroism experiments were also performed to obtain additional information at lower wavelengths, in the ${ }^{1} \mathrm{~B}_{\mathrm{b}}$ region $(180-230 \mathrm{~nm})$. The SRCD spectra of the two enantiomers of 1 recorded in $\mathrm{CH}_{2} \mathrm{Cl}_{2}$ and $\mathrm{CHCl}_{3}$ are reported in Fig. S11 in the ESI. $\dagger$ For wavelengths higher than $230 \mathrm{~nm}$, the SRCD spectra of $\left[\mathrm{CD}(+)_{254}\right]-1$ and $\left[\mathrm{CD}(-)_{254}\right]-1$ are identical in shape and intensities to the ECD spectra described above. For wavelengths lower than $230 \mathrm{~nm}$, the SRCD spectra reveal two additional bands with opposite sign. For instance, the $\left[\mathrm{CD}(+)_{254}\right]-\mathbf{1}$ enantiomer exhibits in $\mathrm{CH}_{2} \mathrm{Cl}_{2}$ a positivenegative bisignate pattern from short to long wavelengths related to the ${ }^{1} \mathrm{~B}_{\mathrm{b}}$ transition. It is noteworthy that similar (in shape and in intensities) SRCD spectra were recorded in $\mathrm{CHCl}_{3}$ solution, in contrast to what was observed for compound $2 .{ }^{17}$

\section{VCD and ROA spectroscopy}

The chiroptical properties of enantiopure cryptophane 1 have been also investigated by VCD in $\mathrm{CDCl}_{3}$ and $\mathrm{CD}_{2} \mathrm{Cl}_{2}$ solutions. The IR spectra of the $\left[\mathrm{CD}(+)_{254}\right]-\mathbf{1}$ enantiomer are similar in the $1700-1000 \mathrm{~cm}^{-1}$ region for the two solutions (Fig. S12 in ESI $\dagger$ ). In addition, the presence of xenon in the $\mathrm{CDCl}_{3}$ solution does not modify the IR spectrum in this spectral range. The VCD spectra of the two enantiomers of 1 measured in $\mathrm{CDCl}_{3}$ and $\mathrm{CD}_{2} \mathrm{Cl}_{2}$ solvents are reported in Fig. S13 in ESI, $\dagger$ whereas the comparison of experimental VCD spectra of $\left[\mathrm{CD}(+)_{254}\right]-\mathbf{1}$ in the two solvents is presented in Fig. 4. As shown in Fig. 4, the VCD spectra of 1 seem independent of the nature of the solvent, even though slight spectral differences are observed in the 1050$1010 \mathrm{~cm}^{-1}$ region. In addition, a slightly lower intensity of the VCD bands is observed in $\mathrm{CD}_{2} \mathrm{Cl}_{2}$ solution, which can be related to the lower molar absorptivities measured in $\mathrm{CD}_{2} \mathrm{Cl}_{2}$ with respect to $\mathrm{CDCl}_{3}$ solution. Finally, the presence of xenon in the $\mathrm{CDCl}_{3}$ solution does not modify the VCD spectrum of $\left[\mathrm{CD}(+)_{254}\right]-\mathbf{1}$ (Fig. S14 in ESI $\dagger$ ).

The ROA spectra of the two enantiomers of 1 measured in $\mathrm{CDCl}_{3}$ solution $(0.1 \mathrm{M})$, in presence or not of xenon, are shown

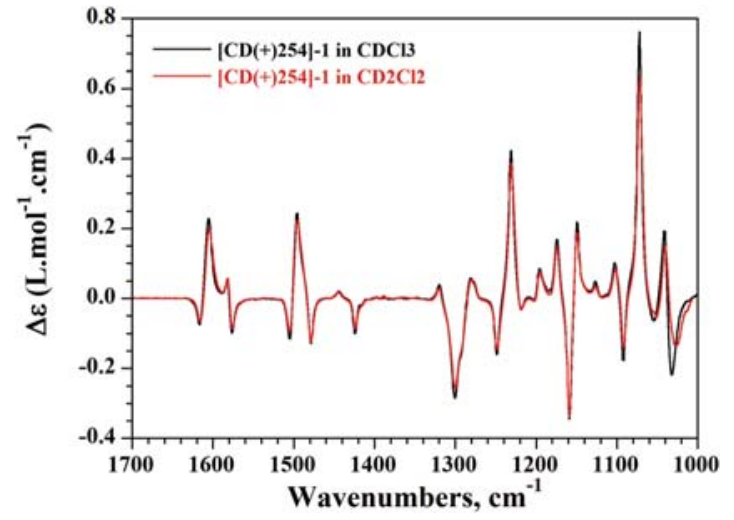

Fig. 4 Comparison of experimental VCD spectra of $\left[C D(+)_{254}\right]-1$ in $\mathrm{CDCl}_{3}$ (black spectrum) and in $\mathrm{CD}_{2} \mathrm{Cl}_{2}$ (red spectrum) solutions.

in Fig. S15 in ESI. $\dagger$ These ROA spectra are nearly perfect mirror images (Fig. S15a and b in ESI $\dagger$ ), as expected for enantiopure materials. The ROA spectra measured in $\mathrm{CD}_{2} \mathrm{Cl}_{2}$ solution were similar (Fig. S15c and d in ESI $\dagger$ ), indicating that the ROA spectra of $\mathbf{1}$ is independent of the solvent, as already mentioned for ECD and VCD experiments. On the other hand, the ROA spectra of $\left[\mathrm{CD}(+)_{254}\right]-1$ in $\mathrm{CD}_{2} \mathrm{Cl}_{2}$ solution in presence or not of xenon reveal a clear spectral difference at wavenumbers lower than $200 \mathrm{~cm}^{-1}$, as shown in Fig. 5. Indeed, in presence of xenon, we observe an important decrease of the intensity of the band at $150 \mathrm{~cm}^{-1}$. The same effect is observed on ROA spectra measured in $\mathrm{CDCl}_{3}$ solution (Fig. S16 in ESI $\dagger$ ). The vibrational assignment of this mode was made by visual inspection of modes represented and animated by using the Agui program. All the displacement vectors of carbon atoms point towards the center of the cavity, indicating that this mode corresponds to the symmetric breathing mode of the cryptophane-111 skeleton. This result clearly indicates that the presence of a guest inside the cavity of a cryptophane derivative modifies the intensity of its symmetric breathing mode. The examination of this mode could be used in the future to reveal the complexation of guest molecules by cryptophane derivatives. However, it is noteworthy that it

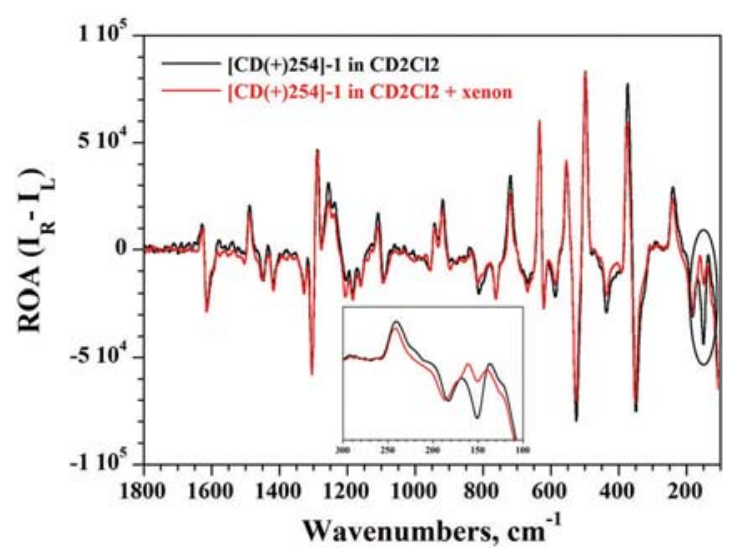

Fig. 5 Comparison of experimental ROA spectra of $\left[C D(+)_{254}\right]-\mathbf{1}$ in $\mathrm{CD}_{2} \mathrm{Cl}_{2}$ solution in presence (red spectrum) or not (black spectrum) of xenon. 
would not be possible to observe this effect for the compound 2 in $\mathrm{CHCl}_{3}$ or $\mathrm{CH}_{2} \mathrm{Cl}_{2}$ solutions, since these two solvent molecules can enter the cavity of $\mathbf{2}$ and would be therefore strong competitors for xenon.

\section{Discussion}

\section{AC and conformational analysis of 1}

As it is now recommended, different techniques have been used to assign unambiguously the absolute configuration (AC) of the two enantiomers of $1 .^{33-35}$ Thanks to the determination of the Flack and Hooft parameters, the X-ray crystallography analysis provides an easy way to determine the $\mathrm{AC}$ of the two $\left[\mathrm{CD}(+)_{254}\right]-1$ and $\left[\mathrm{CD}(-)_{254}\right]-\mathbf{1}$ enantiomers. Thus, based on the analysis of the two X-ray structures, the following assignment $\left[\mathrm{CD}(+)_{254}\right]$ $M M-1$ and $\left[\mathrm{CD}(-)_{254}\right]-P P-\mathbf{1}$ has been found for the two enantiomers of 1. Consequently, considering the specific optical rotation measured at $589 \mathrm{~nm}$ the AC become $(+)_{589}-M M-1$ and $(-)_{589}-P P-1$. It is noteworthy that these last descriptors are identical to those determined for compound 2, as suggested by the similarity observed in their experimental ECD spectra (Fig. 3).

To confirm the AC of the two enantiomers of $\mathbf{1}$, determined by X-ray crystallography, we have used VCD and ROA spectroscopy associated with DFT calculations, which are known to be a valuable approach to assign the AC of organic compounds. Conformer distribution search was performed at the molecular mechanics level of theory for the $M M-1$ configuration, starting from the more symmetrical structure obtained from X-ray analysis of the racemic compound. ${ }^{6}$ Twenty one conformers within roughly $8 \mathrm{kcal} \mathrm{mol}^{-1}$ of the lowest energy conformer were found and their geometries optimized at the DFT level (B3PW91/6-31G**), leading to ten different conformers. The electronic and Gibbs energies as well as the twist angle between the two CTB caps for the three most stable conformers are reported in Table 1 and compared to those calculated from the optimized geometries of the enantiomer crystals. The conformer A leads to the lowest Gibbs free energy and represents more than $99 \%$ of the Boltzmann population of conformers at $298 \mathrm{~K}$. This conformer exhibits the most symmetrical structure with an average value of the twist angle between the two CTB caps of $19.1^{\circ}$ (dihedral angles ${ }^{31}$ of 19.0, 19.1 and 19.1). Conformers B and C present higher twist angles with average values of $23.6^{\circ}$ and $28.7^{\circ}$, respectively. It is noteworthy that the structure is less symmetrical than for conformer A with one

Table 1 Conformations, twist angles and energies of the three conformers of MM-1 calculated from the crystal of $(\mathrm{rac}) \mathbf{- 1}$, and of the one calculated from the crystal of $M M-1$

\begin{tabular}{|c|c|c|c|c|c|}
\hline \multirow[b]{2}{*}{ Conformers } & \multirow{2}{*}{$\begin{array}{l}\text { Twist } \\
\text { angle }\end{array}$} & \multicolumn{2}{|l|}{ Energy (hartrees) } & \multirow{2}{*}{$\begin{array}{l}\Delta G \\
\left(\mathrm{kcal} \mathrm{mol}^{-1}\right)\end{array}$} & \multirow[b]{2}{*}{$\%$} \\
\hline & & Electronic & Gibbs & & \\
\hline $\mathrm{A}$ & 19.1 & -2187.01467627 & -2186.367759 & 0 & 99.7 \\
\hline B & 23.6 & -2187.00811518 & -2186.362379 & 3.38 & 0.3 \\
\hline $\mathrm{C}$ & 28.7 & -2187.00412196 & -2186.359201 & 5.26 & 0.0 \\
\hline Crystal $M M-1$ & 55.3 & -2187.00057700 & -2186.355790 & 7.51 & 0.0 \\
\hline
\end{tabular}

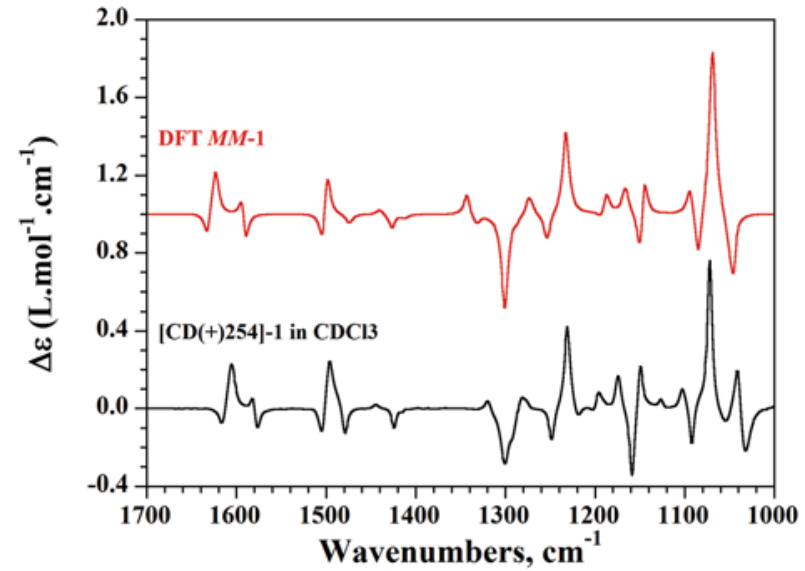

Fig. 6 Comparison of the experimental VCD spectrum of $\left[C D(+)_{254}\right]-1$ recorded in $\mathrm{CDCl}_{3}$ solution with the calculated spectrum at the B3PW91/ $6-31 \mathrm{G}^{\star *}$ level (IEFPCM $=\mathrm{CHCl}_{3}$ ) for conformer $\mathrm{A}$ of $\mathrm{MM-1}$.

dihedral angle, which differs from the two others $\left(21.1^{\circ}, 21.5^{\circ}\right.$ and $28.3^{\circ}$ for conformer $\mathrm{B}$ and $23.8^{\circ}, 31.1^{\circ}$ and $31.2^{\circ}$ for conformer C).

As shown in Fig. 6, the VCD spectrum predicted for the $M M$ configuration of conformer A reproduces very well the sign of most of the bands observed in the experimental spectrum of $\left[\mathrm{CD}(+)_{254}\right]-1$, confirming the AC assignment $\left[\mathrm{CD}(+)_{254}\right]-M M-1$, determined by X-ray crystallography. A very good agreement between predicted ROA spectrum of conformer A and experimental ROA spectrum is also obtained (Fig. S17 in ESI $\dagger$ ). This conformational analysis shows that only one conformer is present for $\mathbf{1}$, contrary to the conformational equilibrium observed for 2 due to the ethylenedioxy linkers (i.e. possibility of trans and gauche conformations of the three linkers). This lack of conformational equilibrium for $\mathbf{1}$ may explain the overall higher intensities of the VCD bands for $\mathbf{1}$ and the lowest FWHM $\left(9 \mathrm{~cm}^{-1}\right.$ for 1 vs. $14 \mathrm{~cm}^{-1}$ for 2) used to reproduce the experimental VCD spectrum for $\mathbf{1}$.

As above mentioned, the bisignate pattern observed in the ${ }^{1} \mathrm{~L}_{\mathrm{a}}$ region (230-260 $\mathrm{nm}$ ) of the ECD spectra of cryptophane derivatives can be another way to determine the AC of these derivatives in organic solvents. ${ }^{16,17}$ Using the Khun-Kirkwood excitonic model, Gottarelli and co-workers have shown that this bisignate resulted from different excited states (one $\mathrm{A}_{2}$ and two degenerate $\mathrm{E}$ components) for cryptophane possessing a $D_{3}$-symmetry. ${ }^{32}$ For the ${ }^{1} \mathrm{~L}_{\mathrm{a}}$ transition, the $\mathrm{A}_{2}$ component is always located at lower energy and the two $\mathrm{E}$ components show opposite rotational strengths. This model leads to a positive/ negative bisignate pattern (from short to long wavelength) for the $M M$ configuration of cryptophane-A derivatives. For cryptophane-111, this bisignate pattern is not observed and this rule does not apply. Indeed, in the case of compound 1, TD-DFT calculations show that the $\mathrm{A}_{2}$ component located at high wavelength possesses a lower negative rotational strength $(R=-0.38 \mathrm{cgs})$ than the one measured for compound 2 $(R=-0.70 \mathrm{cgs})$. Thus, the contribution of the $\mathrm{A}_{2}$ component in the experimental ECD spectrum is embedded in the two E 
components exhibiting a larger rotational strength $(R=1.05 \mathrm{cgs})$, leading to a broader positive band in the ${ }^{1} \mathrm{~L}_{\mathrm{a}}$ region. The strong decrease of the negative $A_{2}$ component of the ${ }^{1} L_{a}$ transition suggests that the classical excitonic coupling model can not be used to determine the AC of cryptophane- 111 molecule and that other contributions should be involved in the interpretation of the ECD spectrum. For instance, as it has been reported by Pescitelli and co-workers in some cases, ${ }^{36,37}$ the coupling between the electric and magnetic transition moments ( $\mu \mathrm{m}$ term) can contribute significantly to the overall rotational strength for a given excited state. This contribution, which is usually neglected in the case of the classical excitonic coupling model, can dominate the electric-electric coupling ( $\mu \mu$ term). Nevertheless, the bisignate pattern observed in the ${ }^{1} \mathrm{~B}_{\mathrm{b}}$ region (190-230 nm) of the SRCD spectra can be used to determine the AC of 1 . Indeed, the positivenegative sequence from short to long wavelength observed for $\left[\mathrm{CD}(+)_{254}\right]-1$ was associated with the $M M$ configuration by TD-DFT calculations (Fig. S18 in ESI $\dagger$ ).

\section{Comparison between the chiroptical properties of 1 and 2}

In a recent article, different behaviours of the chiroptical properties (in particular, polarimetric properties) were observed for 2 in $\mathrm{CHCl}_{3}$ and $\mathrm{CH}_{2} \mathrm{Cl}_{2}$ solutions. ${ }^{17}$ These modifications were interpreted by a subtle conformational equilibrium change of the ethylenedioxy linkers upon encapsulation of $\mathrm{CHCl}_{3}$ and $\mathrm{CH}_{2} \mathrm{Cl}_{2}$ molecules. A preferential $G_{-}$conformation of the linkers was found in $\mathrm{CH}_{2} \mathrm{Cl}_{2}$ solution, in order to decrease the cavity size and to favour hostguest interactions. In contrast, a higher proportion of $G_{+}$conformation of the linkers was found in $\mathrm{CHCl}_{3}$ solution, increasing the size of the cavity suitable for the complexation of chloroform molecule.

The comparison of the chiroptical properties of $\mathbf{1}$ and $\mathbf{2}$ is very interesting because these two compounds possess identical CTB units and differ only by the nature of the alkyl linkers. The conformational equilibrium observed for compound 2 due to the possibility of trans and gauche $\left(G_{+}\right.$and $\left.G_{-}\right)$conformations of the three ethylenedioxy linkers is not possible for compound 1 which possess methylenedioxy linkers. In addition, it has been shown that ( $\mathrm{rac}$-1 $\mathbf{1}$ does not bind halogenomethane molecules so that neither $\mathrm{CH}_{2} \mathrm{Cl}_{2}$ nor $\mathrm{CHCl}_{3}$ can enter its cavity. ${ }^{3,4}$ Thus, no spectral modification in the ECD (or SCRD) and VCD (or ROA) spectra is expected for $\mathbf{1}$ in these two solvents. This assumption is confirmed by our experiments, as shown in the result section.

Our results reveal also that the SOR values of $\mathbf{1}$ behave similarly in the two solvents. We observe a change of the sign of the SOR values in the nonresonant region, as shown in Fig. 3. This surprising effect has been previously reported with compound 2 for experiments in chloroform, acetone and dimethylformamide. Calculations of the SOR at the B3PW91/6-31G** level (IEFPCM $=\mathrm{CHCl}_{3}$ ) reproduce perfectly the experimental data measured in $\mathrm{CHCl}_{3}$ solution (Fig. S19 in ESI $\dagger$ ).

\section{Conclusions}

This article reports a thorough study of the chiroptical properties of the two enantiomers of cryptophane-111 (1) by X-ray crystallography, polarimetry, ECD (SRCD), VCD, and ROA spectroscopy. The absolute configuration of the two enantiomers has been determined based on X-ray crystallographic data. Thus, the $(+)_{589}-M M-1\left((-)_{589}-P P-1\right)$ AC has been assigned. This result has been confirmed by the combined analysis of the VCD (ROA) spectra and DFT calculations. In a second part of this article, the chiroptical properties of $\mathbf{1}$ have been compared to those of cryptophane-222 (2). Despite the similarity in the two structures, derivatives 1 and 2 exhibit different behaviours of their chiroptical properties with respect to $\mathrm{CH}_{2} \mathrm{Cl}_{2}$ and $\mathrm{CHCl}_{3}$ solvents. In these two solvents, polarimetric measurements and SRCD spectra are clearly different for compound 2, whereas they remain almost unchanged for $\mathbf{1}$. This different behaviour can be explained by the incapacity of compound 1 to encapsulate a solvent molecule within its cavity, regardless of the nature of the solvent. Consequently, the nature of the solvent has almost no influence on the conformation of the methylenedioxy linkers. This result confirm our previous assumption that the different chiroptical properties observed for 2 in chloroform and dichloromethane solutions are certainly due to the conformation equilibrium change of the ethylenedioxy linkers upon encapsulation of $\mathrm{CH}_{2} \mathrm{Cl}_{2}$ or $\mathrm{CHCl}_{3}$ molecules.

Thus, the comparison of the chiroptical properties of cryptophane 1 and 2 sheds light on the importance of the solvent present within the cavity to understand the chiroptical properties of the cryptophane derivatives in general. In addition, our results shows that the bulk solvent has no significant effect on the chiroptical properties of $\mathbf{1}$.

\section{Acknowledgements}

Supports from the French Ministry of Research (project ANR12-BSV5-0003 MAX4US) is acknowledged. The authors are indebted to the CNRS (Chemistry Department) and to Région Aquitaine for financial support in VCD and ROA equipments. They also acknowledge computational facilities provided by the MCIA (Mésocentre de Calcul Intensif Aquitain) of the Université de Bordeaux and of the Université de Pau et des Pays de l'Adour, financed by the "Conseil Régional d'Aquitaine" and the French Ministry of Research and Technology. The GDR 3712 Chirafun is acknowledged for allowing a collaborative network between the partners of this project.

\section{Notes and references}

1 A. Collet, Tetrahedron, 1987, 43, 5725.

2 T. Brotin and J.-P. Dutasta, Chem. Rev., 2009, 109, 88.

3 H. A. Fogarty, P. Berthault, T. Brotin, G. Huber, H. Desvaux and J.-P. Dutasta, J. Am. Chem. Soc., 2007, 129, 10332.

4 K. E. Chaffee, H. A. Fogarty, T. Brotin, B. M. Goodson and J.-P. Dutasta, J. Phys. Chem. A, 2009, 113, 13675.

5 T. Traoré, L. Delacour, S. Garcia-Argote, P. Berthault, J.-C. Cintrat and B. Rousseau, Org. Lett., 2010, 12, 960. 
6 R. M. Fairchild, A. J. Akil., K. T. Holman, H. A. Fogarty, T. Brotin, J.-P. Dutasta, C. Boutin, G. Huber and P. Berthault, J. Am. Chem. Soc., 2010, 132, 15505.

7 T. Traoré, G. Clavé, L. Delacour, N. Kotera, P.-Y. Renard, A. Romieu, P. Berthault, C. Boutin, N. Tassali and B. Rousseau, Chem. Commun., 2011, 47, 9702.

8 A. I. Joseph, G. El-Ayle, C. Boutin, E. Léonce, P. Berthault and K. T. Holman, Chem. Commun., 2014, 50, 15905.

9 A. I. Joseph, S. H. Lapidus, C. M. Kane and K. T. Holman, Angew. Chem., Int. Ed., 2015, 54, 1471.

10 A. Bouchet, T. Brotin, D. Cavagnat and T. Buffeteau, Chem. Eur. J., 2010, 16, 4507.

11 A. Bouchet, T. Brotin, M. Linares, H. Agren, D. Cavagnat and T. Buffeteau, J. Org. Chem., 2011, 76, 1372.

12 T. Brotin, R. Montserret, A. Bouchet, D. Cavagnat, M. Linares and T. Buffeteau, J. Org. Chem., 2012, 77, 1198.

13 T. Brotin, D. Cavagnat, P. Berthault, R. Montserret and T. Buffeteau, J. Phys. Chem. B, 2012, 116, 10905.

14 T. Brotin, S. Goncalves, P. Berthault, D. Cavagnat and T. Buffeteau, J. Phys. Chem. B, 2013, 117, 12593.

15 N. Daugey, T. Brotin, N. Vanthuyne, D. Cavagnat and T. Buffeteau, J. Phys. Chem. B, 2014, 118, 5211.

16 T. Brotin, N. Daugey, N. Vanthuyne, E. Jeanneau, L. Ducasse and T. Buffeteau, J. Phys. Chem. B, 2015, 119, 8631.

17 D. Pitrat, N. Daugey, M. Jean, N. Vanthuyne, F. Wien, L. Ducasse, N. Calin, T. Buffeteau and T. Brotin, J. Phys. Chem. B, 2016, 120, 12650.

18 IUPAC Tentative Rules for the Nomenclature of Organic Chemistry. Section E. Fundamental Stereochemistry, J. Org. Chem., 1970, 35, 2849.

19 A. Collet, G. Gabard, J. Jacques, M. Césario, J. Guilhem and C. Pascard, J. Chem. Soc., Perkin Trans. 1, 1981, 1630.

20 A. Giuliani, F. Jamme, V. Rouam, F. Wien, J.-L. Giogetta, B. Lagarde, O. Chubar, S. Bac, I. Yao and S. Rey, et al., J. Synchrotron Radiat., 2009, 16, 835.
21 M. Réfrégiers, F. Wien, H.-P. Ta, L. Premvardhan, S. Bac, F. Jamme, V. Rouam, B. Lagarde, F. Polack and J.-L. Giogetta, et al., J. Synchrotron Radiat., 2012, 19, 831.

22 F. Wien and B. A. Wallace, Appl. Spectrosc., 2005, 59, 1109.

23 J. G. Lees, B. R. Smith, F. Wien, A. J. Miles and B. A. Wallace, Anal. Biochem., 2004, 332, 285.

24 T. Buffeteau, F. Lagugné-Labarthet and C. Sourrisseau, Appl. Spectrosc., 2005, 59, 732.

25 M. J. Frisch, G. W. Trucks, H. B. Schlegel, G. E. Scuseria, M. A. Robb, J. R. Cheeseman, G. Scalmani, V. Barone, B. Mennucci and G. A. Petersson, et al., Gaussian 09, revision A.1, Gaussian Inc., Wallingford CT, 2009.

26 J. P. Perdew and Y. Wang, Phys. Rev. B: Condens. Matter Mater. Phys., 1992, 45, 13244.

27 R. Ditchfield, W. J. Hehre and J. A. Pople, J. Chem. Phys., 1971, 54, 724.

28 J. Tomasi and M. Persico, Chem. Rev., 1994, 94, 2027.

29 J. Tomasi, B. Mennucci and R. Cammi, Chem. Rev., 2005, 105, 2999.

30 B. J. Lynch, P. L. Fast, M. Harris and D. G. Truhlar, J. Phys. Chem. A, 2000, 104, 4811.

31 The twist angle between the two cyclotribenzylene caps is defined by the average dihedral angles between the arene ring centroids of $\mathrm{OCH}_{2} \mathrm{O}$-connected arenes with respect to the $\mathrm{C}_{3}$ axis of the host.

32 J. Canceill, A. Collet, G. Gottarelli and P. Palmieri, J. Am. Chem. Soc., 1987, 109, 6454.

33 P. L. Polavarapu, Chirality, 2008, 20, 664.

34 P. L. Polavarapu, Chirality, 2012, 24, 909.

35 V. P. Nicu, A. Mandi, T. Kurtan and P. L. Polavarapu, Chirality, 2014, 26, 525.

36 T. Bruhn, G. Pescitelli, S. Jurinovich, A. Schaumlöffel, F. Witterauf, J. Ahrens, M. Bröring and G. Bringmann, Angew. Chem., Int. Ed., 2014, 53, 14592.

37 S. Jurinovich, C. A. Guido, T. Bruhn, G. Pescitelli and B. Mennucci, Chem. Commun., 2015, 51, 10498. 